\title{
Correction to: Standard operation procedure for switchSENSE DRX systems
}

\author{
Hanna Müller-Landau ${ }^{1} \cdot$ Paloma Fernández Varela ${ }^{2}(\mathbb{0}$
}

Published online: 29 May 2021

(c) European Biophysical Societies' Association 2021

\section{Correction to: European Biophysics Journal} https://doi.org/10.1007/s00249-021-01519-3

In the original publication of the article, the production team updated the section name "Covalent coupling" twice by mistake. The second section name should be "Capture method".

The original article has been corrected.

Publisher's Note Springer Nature remains neutral with regard to jurisdictional claims in published maps and institutional affiliations.

The original article can be found online at https://doi.org/10.1007/ s00249-021-01519-3.

Paloma Fernández Varela

paloma.fernandez-varela@i2bc.paris-saclay.fr

1 Dynamic Biosensors GmbH, Munich, Germany

2 Université Paris-Saclay, CEA, CNRS, Institute for Integrative Biology of the Cell (I2BC), 91198 Gif-sur-Yvette, France 